\title{
THE EFFECT OF SOCIAL CLOSENESS ON PERCEIVED SATISFACTION OF COLLABORATIVE LEARNING
}

\author{
Shihui Feng ${ }^{1}$, Shuming Qiu${ }^{1}$, David Gibson ${ }^{2}$ and Dirk Ifenthaler ${ }^{3}$ \\ ${ }^{I}$ University Of Hong Kong \\ ${ }^{2}$ Curtin University, Australia \\ ${ }^{3}$ University of Mannheim, Germany; Curtin University, Australia
}

\begin{abstract}
Effective communication and coordination supported by well-established patterns of interactions are vital to collaborative learning. The quality of social relationships among group members can affect group dynamics and communication, as well as further influence students' learning experiences and perceived learning outcomes. In this study, we employ an ego network approach to measure an individual's social closeness with group members and examine effects on the individual's collaborative learning experience. The data was collected through a survey of 120 university students. Our findings indicate that social closeness among group members has a positive effect on the perceived satisfaction of collaborative learning, as students with stronger social closeness with group members tend to be more satisfied with their collaborative learning experience. These results provide advanced theoretical insights for understanding the factors associated with the success of collaborative learning. Based on our findings, appropriate activities for strengthening social closeness among group members are suggested. Implications include pedagogical approaches for facilitating students' collaborative learning experience and outcomes.
\end{abstract}

\section{KEYWORDS}

Collaborative Learning, Group Collaboration, Social Closeness, Tie Strength, Social Network Analysis

\section{INTRODUCTION}

Collaborative learning can be understood as a system-level social activity, in which a group works together to achieve a common goal. The complexity and context of collaboration drives important changes of social ecologies in a group as well as influences the processes of learning (Ifenthaler, 2014; Zuike et al., 2016). Collaboration serves as a mechanism for eliciting a social learning process in which an individual observes and learns from the shared information within a group (Dillenbourg, 1999; Ifenthaler, 2014). The shared space of sense-making within a group forms through active information sharing and inquiring. Social skills are therefore needed for interactions such as coordinating among group members, solving conflicts, negotiating, providing support, and driving group cohesiveness. The importance of social interactions in collaborative learning has been well recognized in previous studies (Miller et al., 1994; Oliver et al., 1998; Rimor et al., 2010; Isohätälä et al., 2017). Through social interactions, individuals' knowledge and perceptions towards a learning task can be enhanced or reshaped (Oliver et al., 1998) so interactions are considered a primary mechanism for individuals to gain new knowledge and improve social skills. Social closeness, defined in detail below, is one measure of social interaction. With the advancement of information technology, blended learning environments supported by various learning analytic tools can enrich the methods for facilitating social interactions in collaborative learning (Chen et al., 2018; Lin et al., 2016). The design of an effective collaborative situation (e.g., who should work together and the duration of the activity) and the social relationships among group members, including social closeness, may thus have a significant influence on group dynamics, as well as the perceived success of a collaborative learning experience (Kerrigan et al., 2021). 
Social network analysis, a method focusing on analyzing social connections among individuals, offers an effective approach to analyze social ties in group collaboration (De Laat et al., 2007). In this study, we employ an ego network approach to explore the effect of social relations among group members on students' perceived satisfaction of collaborative learning, which has been a rather neglected aspect of previous studies on collaborative learning. The research question guiding this study is: Does the strength of a student's social ties have an effect on their perception of collaborative learning?

\section{THEORETICAL BASIS AND HYPOTHESES DEVELOPMENT}

Social closeness represents the extent of connections an individual has with others in a community or group (Nardi, 2005), and has been regarded as a core component of individuals' perceived social support (Sarason et al., 1987). Consequently, social closeness has been a long-standing research interest in psychology and sociology. The level of closeness children and young adults have with family members is suggested to be associated with their psychological development and behavioral preferences (Euler et al., 2001; Murray et al., 2005; Roberts et al., 2001; Ledbetter, 2009). In this study, the operational definition of social closeness in collaborative learning refers to an individual's perceived strength of relationships with group members. Social closeness among group members can be built on time spent together, mutual benefits, and social friendship. According to social interdependence theory, social structure largely influences the types of interactions in a group setting (Johnson \& Johnson, 2009). Cohesive social relations, for example, have a positive influence on the intensity of interactions (Kawachi \& Berkman, 2000; Lin et al., 2016). The social closeness among group members in collaborative learning could be positively associated with the perceived social support of individuals, and therefore close social relationships within a group could lead to a trusting and cohesive learning environment and further improve active engagement of individuals in the learning process, which can further enhance learning outcomes and levels of satisfaction.

Various psychometric instruments for measuring social closeness have been proposed in previous studies based on context and study population (Aron et al., 1992; Burnett \& Demnar, 1996; Ifenthaler, 2014; Popovic et al., 2003). Unlike psychometric approaches, social network analysis offers a theory-based method to assess social ties based on the structural characteristics of captured social connections (Wasserman \& Faust, 1994). In a network, social closeness can be measured based on the strength of ties between the connected actors (Ifenthaler, 2010). Granovetter (1977) developed weak tie theory, which suggests that tie strength in a network plays a critical role in determining the effectiveness and novelty of information sharing and acquisition. Weak ties exist in more casual relationships with less time or emotional exchange and input, and are effective for acquiring new information and making progress, for instance in job seeking or status attainment (Granovetter, 1977). By contrast, strong ties indicate a high level of perceived closeness, intimacy, and high frequency of interactions, and are more effective in maintaining stable relations and increasing social affinity. In this study, we adopt an ego network approach to construct the collaboration network of each participant, based on which the social closeness of the individual is gauged by the average strength of ties in the constructed ego networks.

Ego networks are the networks revealing the social connections of an individual rather than the social relationships among a group of people (Wasserman \& Faust, 1994; Borgatti et al., 2009). In an ego network, the ego (focal) node represents the individual that is the focus of interest, and edges represent the social ties that the individual has with others (alters). The links between ego and the alters are characterized by the strength of ties between them. The ego network approach is widely adopted in anthropology to model and analyze individuals' social connections. In this study, an ego network approach is used to capture the social relationships of individual students with their group members in small-team collaborative learning, and the average strength of social ties in an individual's ego network is used to measure their perceived social closeness with group members in a collaborative learning process. A higher value of average strength indicates a stronger social closeness with group members. Following previous research findings, the hypothesis of this study is:

$\mathrm{H}_{0}$ : There is no correlation between students' average social tie strength in their ego networks and their satisfaction with collaborative learning experiences.

$\mathrm{H}_{1}$ : Students with higher average social tie strength in their ego networks are more satisfied with their collaborative learning experiences. 


\section{METHODS}

\subsection{Participants and Procedures}

In this study, a web-based questionnaire including 19 items was administered in October 2018. The questionnaire was distributed to university students who had participated in any kind of group project in their study program. They completed the survey based on their most recent experience of collaborative learning. The informed consent form - which included the information about research purpose, procedures, data management, and approved ethics for the study - was attached in the first page of the questionnaire. The questionnaire includes three parts: 1) demographic information (including age, gender, academic year, major); 2) items for constructing an individual's ego-network and tie strength; 3) items focusing on the perceived satisfaction of the collaborative learning experience. The items for measuring social closeness and perceived satisfaction of collaborative learning are provided in the subsection below. 120 students from a university in Hong Kong were randomly invited to participate in this study. After screening out the incomplete responses, 109 valid responses (out of 115 responses in total) were received. The average age of participants in the sample was $23(S D=1.491)$. Among the participants, 70 students were female $(64.2 \%)$ and 39 were male $(35.7 \%)$. There were 67 students $(61.5 \%)$ who majored within science and engineering and 42 students (38.5\%) who majored within arts, social sciences, or humanities. The beginning of the questionnaire asked about the frequency of the student's participation in group-based collaborative projects, to ensure that each valid responder had experienced collaborative learning in their study program. Respondents were asked to answer questions about their perceived closeness to group members and satisfaction level based on their latest experience in group-based collaborative projects.

\subsection{Measures}

\subsubsection{Social Closeness}

The average tie strength of ego networks was used to measure the social closeness of participants towards other members in a collaboration group. In the questionnaire, responders (egos) were asked to recall the latest experience of group work in his/her academic program and answer questions such as "Who were your group members (alters)?", and "How close did you feel to each of listed group member?". Social closeness with each group member was measured using a five-point Likert scale $(1=$ not close at all, $5=$ very close $)$. Ego networks for all respondents were constructed based on the collected information. Figure 1 below shows an example of an ego network of one responder in this study. This responder (' $\mathrm{R} 1$ ') had five group members in a group project and the perceived closeness or strength of relationships with the five group members is illustrated through the thickness of the links. The social closeness of this student to their other group members is measured by the mean value of the sum of weights of all links in the ego network. The social closeness of each participant with their group members is acquired using this approach.

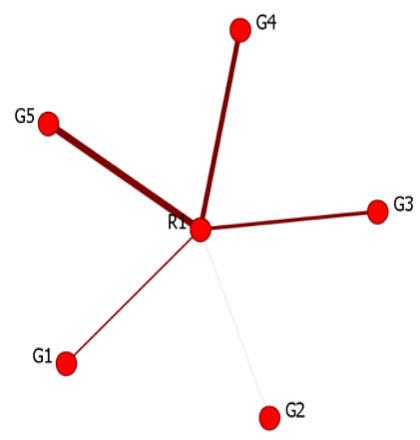

Figure 1. Participant ego network example, with edge thickness representing tie strength as measured through the questionnaire 


\subsubsection{Perceived Satisfaction of Collaborative Learning}

In the questionnaire, responders were also invited to answer questions about their satisfaction towards the same collaborative learning experience. The items for measuring the perceived satisfaction of collaborative learning are presented in Table 1. These items were created based on the characteristics of successful collaborative learning proposed by Dillenbourg (1999), which include: (1) average division of labor; (2) effectiveness of communication and negotiation; (3) shared understanding among group members; (4) acquisition of new knowledge through the learning process. All items were measured using five-point Likert-type scales ( $1=$ strongly disagree, $5=$ strongly agree). The factor loadings of each item were all above 0.5 (see Table 1 below) and the Cronbach's $\alpha$ of all items was .837, indicating that this scale for measuring the perceived satisfaction of collaborative learning shows a high level of reliability.

Table 1. Factor loadings of individual items

\begin{tabular}{|l|l|}
\hline \multicolumn{1}{|c|}{ Items } & \multicolumn{1}{|c|}{ Factor loading } \\
\hline The division of the workload was reasonable in my group. & .754 \\
\hline Group members actively exchanged ideas with each other. & .704 \\
\hline There were no difficulties in communicating with my group members. & .592 \\
\hline It was easy to achieve consensus in my group. & .658 \\
\hline $\begin{array}{l}\text { I could get help from my group members when I encountered difficulties } \\
\text { in group work. }\end{array}$ & .542 \\
\hline $\begin{array}{l}\text { By discussing with my group members, I developed new skills and } \\
\text { knowledge. }\end{array}$ & .789 \\
\hline Overall, I was satisfied with my collaborative learning this time. & .811 \\
\hline
\end{tabular}

\section{RESULTS}

\subsection{The Impact of Demographic Factors on Social Closeness and CL}

The examined demographic information of participants includes age, gender, and study major. An independent samples t-test was performed to test whether responders with different demographic characteristics had differences in their perceived social closeness to their group members and their perceived satisfaction of collaborative learning. First, we tested the influence of gender on perceived social closeness and satisfaction in collaborative learning. According to the collected data, there was no significant difference, as female $(M=4.09, S D=0.70)$ and male students $(M=4.14, S D=.56)$ did not differ significantly in their perceived closeness with their group members, $t(107)=.380, p=.7047$. Male students $(M=3.66, S D=.33)$ had a significant higher satisfaction level with their collaborative learning experience than female students $(M=3.43$, $S D=.61), t(107)=2.545, p<.05$. Second, we tested whether or not students from different majors behave differently regarding their perceived social closeness and satisfaction in their collaborative learning experience. Students were classified into two groups based on their majors, with responders studying science and engineering classified into one group and students in social sciences, arts and humanities classified into the other group. We find there was no significant difference in the perceived satisfaction of collaborative learning of students majoring in science $(M=3.48, S D=.43)$ and students majoring in social sciences $(M=3.63$, $S D=.47), t(107)=-1.604, p=.112$. There was also no significant difference in social closeness with group members of students majoring in science $(M=4.19, S D=.62)$ and students majoring in social sciences $(M=4.02, S D=.60), t(107)=-1.376, p=.172$. Third, the influence of age on the perceived social closeness and satisfaction in CL was also tested. According to the results of a Pearson correlation analysis, there was no significant correlation between age and the two studied variables, $r(107)=.110, p=.344$. In summary, individuals' social closeness to their group members and perceived satisfaction with collaborative learning were not influenced by their age or academic discipline, but there was a significant difference between male and female students in their satisfaction with collaborative learning. 


\subsection{The Impact of Social Closeness on $\mathbf{C L}$}

Correlation analysis was conducted to test the relationship between individuals' social closeness to their group members and their perceived satisfaction with their collaborative learning experience. Based on Pearson correlation analysis, we found a significant correlation between perceived social closeness and perceived satisfaction with collaborative learning $(r=.210, p<.05)$, which allows us to reject $\mathrm{H}_{0}$, indicating that individuals' social closeness with group members is significantly associated with their perceived satisfaction with collaborative learning. The individuals with a close social relationship with their group members tended to be more satisfied with their collaborative learning experience. A linear regression analysis was further conducted to test the predictability of social closeness and gender on collaborative learning. It was verified that social closeness was a significant predictor of perceived satisfaction of collaborative learning $(\beta=.151$, $p<.05)$. The variables of social closeness together with gender explained $9.8 \%$ of the variance of the perceived satisfaction of collaborative learning. While the explanatory capacity of one independent variable on perceived satisfaction of collaborative learning is limited, it provides a significant explanation of individuals' perceived satisfaction of collaborative learning, and so this result provides a theoretical contribution to our understanding of this process. Accordingly, the hypothesis is accepted, students with higher average social tie strength in their ego networks are more satisfied with their collaborative learning experiences.

\section{DISCUSSION}

This research examines the relationship between social closeness within a collaboration group and students' perceived satisfaction with collaborative learning. Findings indicate that an individual's perceived social closeness to their group members has a positive association with their satisfaction with collaborative learning. Students who had a closer social relationship with their group members tended to be more satisfied with the collaborative learning experience. This study contributes empirical evidence of the importance of social ties in collaborative learning. Based on this finding, we provide advanced evidence-based insights into instructional design of collaborative learning in educational practice in the paragraphs below.

The rationale for understanding the positive influence of social closeness on perceived satisfaction with collaborative learning can be considered from two perspectives. First, social closeness can increase trust among group members, which can facilitate information sharing and individual engagement in the collaborative learning process (Lin et al., 2016). Second, social closeness can create an inclusive social environment, which can enhance participation by facilitating negotiations and conflict solving among group members. Wilson (2010) highlighted that trust has a positive influence on the willingness of information sharing and also plays an intermediating role in adjusting the competing effects of risk and reward on information sharing. A close social relationship may indicate a level of interpersonal trust, and may have an impact on the willingness of information sharing among group members. Previous studies have highlighted that information sharing and interactions among group members are key to the success of collaborative learning (Dillenbourg, 1999; Ifenthaler, 2014; Vuopala et al., 2016). Beyond that, close social relationships among group members also facilitates an inclusive social environment in which open communication and effective negotiation can be achieved on the basis of mutual understanding and tolerance. Wang (2009) found that forming groups based on friendship can enhance the effectiveness of collaborative learning by creating a harmonious social atmosphere and allowing members to reach agreement about regulations of the collaboration. Close social relationships among group members can promote trust and an inclusive social environment, which can further facilitate information sharing, individual engagement, and consensus driving, as well as create a pleasant social space for collaborative learning processes. In addition to the effect of social closeness on perceived satisfaction of collaborative learning, this study also found that there is a gender difference in the perceived satisfaction of collaborative learning. Male students had an overall higher level of satisfaction of their collaborative learning experience than female students. This result can be interpreted based on Eagly's social role theory (1987) that gender differentiated skills could affect feelings associated with activities. However, the previous study by González-Gómez et al. (2012) found that female students tended to be more satisfied than male students in online learning. Here, we suggest future studies further examine the gender difference in perceived satisfaction of collaboration learning with a larger sample size. 
Based on our findings, practical strategies can be applied in instructional design and group management in order to build social closeness among group members in collaborative learning. First, empower students to organize their own collaborative learning groups based on their own social connections and preferences. Ramírez-Correa and Fuentes-Vega (2015) put forward three factors affecting the formation of collaborative learning groups which include homophily, academic performance, and level of happiness. Students like to work with peers who are similar to themselves and have similar academic performance (Ramírez-Correa \& Fuentes-Vega, 2015). It is thus easier for students to develop close social relationships with group members selected by themselves rather than arranged by instructors. Freedom to organize their own groups can facilitate the development of a shared sense-making space among group members, as well as effectively aid in achieving consensus in group discussions. Instructional design should also provide time and support for group members to build or strengthen closeness among the members of a team to facilitate a positive perception of the group experience.

Second, incorporating activities for developing group members' social closeness in collaborative learning. Multiple techniques have been proposed with an aim to facilitate social interactions in computer-supported collaborative learning (Bluemink et al., 2010; Johnson et al., 2009; Kobbe et al., 2007). In offline collaborative learning, in addition to the required learning tasks for achieving collaborative learning objectives, group building activities can be introduced at the beginning to help students know their prospective group members better, build social connections, as well as create a more active and relaxing atmosphere for students to conduct collaborative activities. The group building activities should not be complicated but require strong cooperation and coordination among group members. Incorporating group building activities in collaborative learning is important, in particular for the individuals who are new to a study program and have no prior collaboration experience with peers in the program. Group building activities can then help them gain familiarity and develop social connections with each other, which could effectively facilitate the development of social closeness and allow them to achieve more satisfaction with their collaborative learning.

\section{CONCLUSION}

Engaging students in collaborative learning has always been an important consideration for instructors, and the findings of this study provide advanced theoretical and practical insights for understanding collaborative learning from a social perspective. The success of collaborative learning is partially determined by an effective social learning environment that supports intensive engagement and interactions among group members. In addition to instructional methods for facilitating students' engagement in the learning process, appropriate guidance and intervention should also be integrated to help students develop social closeness with their group members, as this can further enhance the effectiveness of collaborative learning. Future studies are recommended to further test the effect of social closeness with a larger sample size as well as in both online and offline settings. Mixed methods are recommended to further elaborate the theoretical underpinnings for understanding these effects, are suggested for future research.

\section{ACKNOWLEDGMENT}

We would like to thank Dr Van Aalst, Jan C. W for valuable discussions and comments on the manuscript. This research is supported by Curtin University's UNESCO Chair of Data Science in Higher Education Learning and Teaching (https://research.curtin.edu.au/unesco/).

\section{REFERENCES}

Aron, A., Aron, E. N., \& Smollan, D. (1992). Inclusion of other in the self scale and the structure of interpersonal closeness. Journal of personality and social psychology, 63(4), 596.

Bluemink, J., Hämäläinen, R., Manninen, T., \& Järvelä, S. (2010). Group-level analysis on multiplayer game collaboration: how do the individuals shape the group interaction?. Interactive Learning Environments, 18(4), 365-383. 
Borgatti, S. P., Mehra, A., Brass, D. J., \& Labianca, G. (2009). Network analysis in the social sciences. science, 323(5916), 892-895.

Burnett, P. C., \& Demnar, W. J. (1996). The relationship between closeness to significant others and self-esteem. Journal of Family Studies, 2(2), 121-129.

Chen, B., Chang, Y. H., Ouyang, F., \& Zhou, W. (2018). Fostering student engagement in online discussion through social learning analytics. The Internet and Higher Education, 37, 21-30.

De Laat, M., Lally, V., Lipponen, L., \& Simons, R. J. (2007). Investigating patterns of interaction in networked learning and computer-supported collaborative learning: A role for Social Network Analysis. International Journal of Computer-Supported Collaborative Learning, 2(1), 87-103.

Dillenbourg, P. (1999). Collaborative-learning: Cognitive and Computational Approaches., Oxford: Elsevier, pp.1-19,

Eagly, A. H. (1987). Sex differences in social behavior: A social-role interpretation. Earlbaum, Hillsdale, NJ

Euler, H. A., Hoier, S., \& Rohde, P. A. (2001). Relationship-specific closeness of intergenerational family ties: Findings from evolutionary psychology and implications for models of cultural transmission. Journal of Cross-Cultural Psychology, 32(2), 147-158.

González-Gómez, F., Guardiola, J., Rodríguez, Ó. M., \& Alonso, M. Á. M. (2012). Gender differences in e-learning satisfaction. Computers \& Education, 58(1), 283-290.

Granovetter, M. S. (1977). The strength of weak ties. In Social networks (pp. 347-367).

Ifenthaler, D. (2010). Scope of graphical indices in educational diagnostics. In D. Ifenthaler, P. Pirnay-Dummer, \& N. M. Seel (Eds.), Computer-based diagnostics and systematic analysis of knowledge (pp. 213-234). Springer.

Ifenthaler, D. (2014). Toward automated computer-based visualization and assessment of team-based performance. Journal of Educational Psychology, 106(3), 651-665. https://doi.org/10.1037/a0035505

Isohätälä, J., Järvenoja, H., \& Järvelä, S. (2017). Socially shared regulation of learning and participation in social interaction in collaborative learning. International Journal of Educational Research, 81, 11-24.

Johnson, D. W., \& Johnson, R. T. (2009). An educational psychology success story: Social interdependence theory and cooperative learning. Educational researcher, 38(5), 365-379.

Johnson, T. E., Ifenthaler, D., Pirnay-Dummer, P., \& Spector, J. M. (2009). Using concept maps to assess individuals and team in collaborative learning environments. In P. L. Torres \& R. C. V. Marriott (Eds.), Handbook of research on collaborative learning using concept mapping (pp. 358-381). Information Science Publishing.

Kawachi, I., \& Berkman, L. (2000). Social cohesion, social capital, and health. Social epidemiology, 174(7).

Kerrigan, S., Feng, S., Vathaluru, R., Ifenthaler, D., \& Gibson, D. C. (2021). Network analytics of collaborative problem-solving. In D. Ifenthaler, D. G. Sampson, \& P. Isaias (Eds.), Balancing the tension between digital technologies and learning sciences. (pp. 53-76). Springer.

Kobbe, L., Weinberger, A., Dillenbourg, P., Harrer, A., Hämäläinen, R., Häkkinen, P., \& Fischer, F. (2007). Specifying computer-supported collaboration scripts. International Journal of Computer-Supported Collaborative Learning, $2(2-3), 211-224$

Ledbetter, A. M. (2009). Family communication patterns and relational maintenance behavior: Direct and mediated associations with friendship closeness. Human Communication Research, 35(1), 130-147.

Lin, L., Mills, L., \& Ifenthaler, D. (2016). Collaboration, multi-tasking and problem solving performance in shared virtual spaces. Journal of Computing in Higher Education, 28(3), 344-357. https://doi.org/10.1007/s12528-016-9117-x

Miller, J. E., Trimbur, J., \& Wilkes, J. M. (1994). Group dynamics: Understanding group success and failure in collaborative learning. New directions for teaching and learning, 1994(59), 33-44.

Murray, S. L. (2005). Regulating the risks of closeness: A relationship-specific sense of felt security. Current Directions in Psychological Science, 14(2), 74-78.

Nardi, B. A. (2005). Beyond bandwidth: Dimensions of connection in interpersonal communication. Computer Supported Cooperative Work (CSCW), 14(2), 91-130.

Oliver, R., Omari, A., \& Herrington, J. (1998). Exploring student interactions in collaborative World Wide Web learning environments. Journal of Educational multimedia and Hypermedia, 7(2/3), 263-287.

Popovic, M., Milne, D., \& Barrett, P. (2003). The scale of perceived interpersonal closeness (PICS). Clinical Psychology \& Psychotherapy: An International Journal of Theory \& Practice, 10(5), 286-301.

Ramírez-Correa, P., \& Fuentes-Vega, C. (2015). Factors that affect the formation of networks for collaborative learning: an empirical study conducted at a Chilean university. Ingeniare. Revista chilena de ingeniería, 23(3), 341-347.

Rimor, R., Rosen, Y., \& Naser, K. (2010). Complexity of social interactions in collaborative learning: The case of online database environment. Interdisciplinary Journal of E-Learning and Learning Objects, 6(1), 355-365.

Roberts, B. W., Caspi, A., \& Moffitt, T. E. (2001). The kids are alright: growth and stability in personality development from adolescence to adulthood. Journal of personality and social psychology, 81(4), 670. 
Sarason, I. G., Sarason, B. R., Shearin, E. N., \& Pierce, G. R. (1987). A brief measure of social support: Practical and theoretical implications. Journal of social and personal relationships, 4(4), 497-510

Vuopala, E., Hyvönen, P., \& Järvelä, S. (2016). Interaction forms in successful collaborative learning in virtual learning environments. Active Learning in Higher Education, 17(1), 25-38.

Wang, Q. (2009). Design and evaluation of a collaborative learning environment. Computers \& Education, 53(4), 1138-1146.

Wasserman, S., \& Faust, K. (1994). Social network analysis: Methods and applications (Vol. 8). Cambridge university press.

Wilson, T. D. (2010). Information sharing: an exploration of the literature and some propositions. Information Research: an International Electronic Journal, 15(4), n4.

Zuiker, S. J., Anderson, K. T., Jordan, M. E., \& Stewart, O. G. (2016). Complementary lenses: Using theories of situativity and complexity to understand collaborative learning as systems-level social activity. Learning, Culture and Social Interaction, 9, 80-94. 